\title{
We are all connected: Globalization and community sustainability in the boreal forest, an Aboriginal perspective
}

\author{
by Garry Merkel ${ }^{1}$
}

\begin{abstract}
This paper summarizes my personal perspective on the impacts of globalization on the sustainability of aboriginal communities. Globalization affects communities through changes to the land and the plants and animals it supports, the demographic profiles of the people increasingly through migration, their lifestyles, the persistence of their language and philosophy to living on the land, and their values. At the same time the people are learning to develop businesses, improve community services, and protect their interests through international recognition of their rights. Success in dealing with globalization will depend on the ability of the communities to develop a) appropriate systems of governance, b) mechanisms to accommodate their traditions in the context of contemporary culture, c) networks from the local to international levels, and most importantly d) their own capacities so that they no longer rely on the external "expert/consultant." The forest sector has a role to play in this process by developing a true partnership with the communities on whose land they hope to operate. This includes getting to know the people and their values, treating their knowledge with respect, and assisting them to develop their own capacities. Acting on the fact that we are all connected means that these partnerships will work to our mutual benefit. The distance we have to travel to make these changes may be as little as 6."
\end{abstract}

Key words: Aboriginal communities, Globalization impacts, Forest sector, Working relationships

\section{RÉSUMÉ}

Cet article constitue un résumé de ma vision personnelle des impacts de la mondialisation sur la durabilité des communautés autochtones. La mondialisation affecte les communautés par suite des changements qu'elle génère au sein du territoire et parmi les plantes et les animaux qu'il supporte, elle modifie les profils démographiques des gens de plus en plus par la migration, ainsi que leurs modes de vie, la résilience de leur langue et de leur philosophie d'existence sur un territoire donné et de leurs valeurs. Au même moment, les gens apprennent à développer des entreprises, à améliorer les services collectifs et à protéger leurs intérêts par une reconnaissance internationale de leurs droits. Il sera possible de réussir à faire face à la mondialisation en fonction de la capacité des communautés à développer a) des systèmes appropriés de gouvernance, b) des mécanismes d'accommodements de leurs traditions dans le contexte culturel contemporaine, c) des réseaux allant des niveaux locaux aux niveaux internationaux et le plus important d) leurs propres capacités de façon à ne plus être dépendants de "consultants/experts » externes. Le secteur forestier a un rôle à jouer dans ce processus en mettant en place un vrai partenariat avec les communautés dont les territoires pourraient faire l'objet d'exploitation. Cela comprend la connaissance des gens et de leurs valeurs, du respect de leurs connaissances et l'aide au développement de leurs propres capacités. En tenant compte que nous sommes tous inter-reliés, ces partenariats pourront fonctionner tout en étant mutuellement bénéfiques. La distance que nous avons à parcourir pour réaliser ces changements pourrait être vraiment courte.

Mots clés : communautés autochtones, impacts de la mondialisation, secteur forestier, relations fonctionnelles

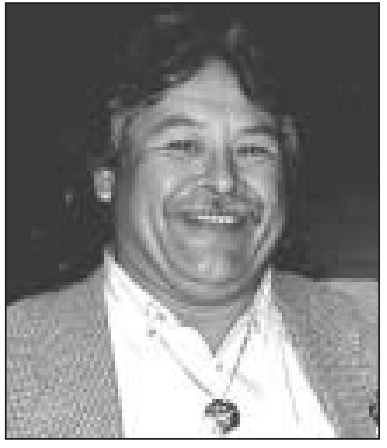

Garry Merkel

\section{Introduction}

This summarizes my thoughts on globalization and community sustainability in the boreal forest from an aboriginal perspective. This paper is based on my invitation by the Canadian Institute of Forestry to present my views to the Annual General Meeting in Cochrane, Ontario on October 3, 2006. The organizers asked me to speak on the following questions with an emphasis on the last two regarding aboriginal impacts and perspectives.

1. What are the critical forces of changes associated with globalization?

2. What will these forces of change mean to the North American boreal forest?

3. What actions should be taken to respond to these forces of change?

4. How are aboriginal communities in the boreal forest region of Canada facing the challenges associated with globalization?

5. From an aboriginal perspective- - how should the forest sector be transformed to better address the effects of globalization and ensure community sustainability?

${ }^{1} 466$ - 2nd Ave., Kimberley, British Columbia V1A 2P7. E-mail: gmerkel@telus.net 
By way of background, I begin with the following more general thoughts when considering the questions.

- For me, something does not appear intuitive when I see globalization and aboriginal communities in the same sentence. On one hand, Aboriginal communities tend to be relatively isolated from the rest of the world, but on the other hand globalization is a world-wide force. Somehow they just did not seem to fit, but as I pondered this it became very clear that aboriginal communities, particularly in the boreal forest region, are greatly affected by globalization.

- Aboriginal communities in the boreal forest region tend to be more land-based and less prepared for change, particularly when the source of change comes from far away. This was emphasized to me in recent discussions with various Elders in northern Saskatchewan. They were very concerned about, and had attended a few aboriginal healers' conferences on how to deal with, the new pandemic. After some probing I asked if they were talking about bird flu. They said no-this was a pandemic. Further discussions with others and recipes provided to me by the Elders showed that they were talking about the highly publicized bird flu. However, they were generally not aware of the term bird flu or the high media attention it has received.

- Boreal forests tend to be more fragile than many other forest ecosystems. It can take many decades if not hundreds of years for these systems to recover from impacts that may only take years or possibly a few decades in more robust forest ecosystems.

\section{Effects of Globalization on Aboriginal Communities}

The general symptoms of globalization that are often cited in the literature are summarized in the text box. The symptoms of globalization that I have observed in aboriginal communities in the boreal forest region are summarized below.

a) The land has changed in big ways, largely because of climate change that in turn is a direct symptom of globalization. Things such as caribou migration patterns and access to the northern boreal forests have changed drastically because of the loss of permafrost. This is not to mention other devastating symptoms such as the Mountain Pine Beetle epidemic in British Columbia. The types of resources (animals and plants) are changing, and where and how we access the boreal landscape is changing. These changes mean that aboriginal people who live off the land cannot use the land in the same ways, and in some cases cannot use the land at all.

b) Increased exposure to alternative life styles has generally decreased the aboriginal community's dependence on the land for sustenance, particularly among the younger population. This means that skills such as trapping, hunting, fishing, gathering, and the collection and use of medicinal plants are slowly being lost. Families are spending more time in front of the television, computer or video games to fill the time that would otherwise be spent in these traditional pursuits.

c) Many aboriginal languages are or are nearly extinct. There is no practical need for these languages in our modern global world. However, the loss of these languages also carries the loss of the underlying philosophical foundations and associated spirituality embodied within these languages. One small example that I believe illustrates the consequences of this loss stems from the fact that the words or idea of "weed" or "own" do not exist in any of earth-based languages with which I am familiar. These societies are built on the premise that everything has a place; therefore, there are no weeds, that everything is on loan, and that we are the ones who are "owned." This type of thinking is essential if our contemporary society is to change its lifestyle in order to address the environmental global issues that face us.

d) Many aboriginal communities are developing a much stronger materialistic orientation to the land (although some had this before globalization). Bigger, better and disposable has been adopted as the thinking of the day. One example that illustrated this to me was in the Artic when I saw the Inuit hunters let their snowmobiles (many of which were new that year) simply float out to sea on the ice floes. Their response was, "I can always get another (bigger and better) one."

e) Aboriginal communities are now subject to much greater public scrutiny and accountability. While this is generally a positive trend, it also yields the significant tension that is associated with any type of intense growth. Many communities are working as hard as they can to improve their governance and build their internal capacity. World class institutions such as the Harvard University have also joined the cause, and are dedicating serious support in the form of research and extension to assist aboriginal communities through these changes.

f) Potential business opportunities have increased exponentially for the aboriginal community. The global marketplace generally favours companies that have a positive business track record with aboriginal communities. This has created significant pressure on aboriginal communities because everyone (good or bad) suddenly wants to become
Symptoms of globalization include: cybernetic revolution; rise of popular culture; international mass migration of labour; weakened status of independent countries; growth of corporate power (social, economic, environmental); urbanization; increased consumerism; spread of democracy; open borders and spaces; increased interconnectedness; accelerated resource depletion and impacts; improved health care; and improved living conditions. 
your friend. Slow and steady would be the prudent way to proceed given most aboriginal communities' lack of experience in the business world, particularly at the global level. However, internal pressures for more, more, more cause many communities to make quick decisions that often end up creating more pain than yielding benefits.

g) Globalization means that most aboriginal communities now have better services, particularly with respect to education and health services. Transportation systems are better, it is easier to bring expert help into remote areas for short periods of time, it is easier to bring patients to centres, and it is easier to bring the world to remote communities' front doors through the internet. Many communities have some type of high-speed internet technology and almost all at least have dial-up.

h) Many northern aboriginal communities are experiencing a large scale migration away from community, particularly among young people. They are coaxed away to pursue the materialistic dream that is fostered through the global television network. Many of these individuals make it to the closest larger centre where they face many dangers-many do not survive. The rate of abuse, teenage death, suicide and run-ins with the law among aboriginal youth is many times higher than the national average.

i) Aboriginal communities are generally more able to protect their interests in their lands because of the general sense of injustice towards indigenous peoples that has becoming more recognized at a global level. International scrutiny has yielded various protective instruments such as the Forest Stewardship Council's Principle 3, which recognizes and protects indigenous peoples' customary and legal rights. This pressure, plus the changing legal landscape in Canada, has enticed many companies to negotiate some form of Impacts Management and Benefits Agreements (IMBA) with aboriginal communities.

j) Many aboriginal communities are experiencing increased infringement, manipulation and marginalization by outside interests. The primary culprits include environmental groups, industrial interests and pharmaceutical companies. The environmental movement has become a global corporate player and most have adopted mandates that place indigenous peoples second to their primary environmental causes. One harmful tactic that I have personally observed numerous times is where an NGO will take advantage of the inherent turmoil in most aboriginal communities. The NGO will invest resources in a small group and use that group as a pawn to foster the NGO's interest through a global campaign in isolation of the rest (and often majority) of the community. This tactic fosters longterm divisions in many of these communities that may never heal. The net result for many of these communities is that they are relegated to a permanent societal backwater. They can never get over their internal divisions in order to move on to the collective approach required to improve their social situation. I have observed industrial interests using this same tactic; however, they are less willing to use it these days because of increased public awareness and scrutiny. Being caught carries serious potential harm to their business credibility and bottom line-factors that do not carry the same consequences within the environmental community. Pharmaceutical companies have also proved to be very insidious in trying to gain access to the next "wonder cure" that probably resides in some indigenous community. I have heard many personal accounts of these companies using indigenous spies to infiltrate a community and gain access to confidential local knowledge. Once gained, this knowledge is most often exploited without any credit or sharing of benefits back to the original source.

\section{Responses to Globalization}

So how are aboriginal communities responding to these changes? My observations are generally - NOT WELL. Many communities that I work with have an ideal vision of staying the same or going back to what they were. Most are forced to resign to the fact that this is here to stay and have to then deal with the question of, "How do we deal with these changes?" This is in the face of already constantly adapting to an unprecedented pace of change at all levels within the community. While this may be seen as a positive force, change is generally a painful process and often takes a negative toll on all aspects of a community. This is particularly true in cases such as the boreal aboriginal communities where capacity to deal with change is generally limited.

Each community is responding differently to the forces of globalization. Some are frustrated and would rather that the world just left them alone, particularly in cases where these forces are serving to further marginalize them from society at large. Some have embraced the forces of globalization and are harnessing these forces to their advantage. Most of these communities are using these forces to foster strong local economies; however, a few are using them to support a strong protection of lands and traditional culture focus. Regardless of the focus, using these outside and often foreign forces tends to intensify internal tensions between those who want to make a modern-day living and those who want things to stay the same.

Communities that have achieved some success in dealing with the forces of globalization generally share the following key characteristics:

- The community is making a concerted effort to develop its internal governance discipline and has developed the associated internal capacity to achieve its desired level of discipline. A huge body of international research (initiated by and commonly known as the Harvard project) on developing communities has shown that the communities' level of governance discipline and capacity is the key factor in determining a community's long-term success.

- The community has established a number of internal mechanisms to support and to preserve and enhance its traditional culture while learning to accommodate contemporary culture within this context. In essence these communities are working hard at becoming bi-cultural or multi-cultural.

- The community clearly understands the use of technology as a tool and has developed internal methods to use technology to its advantage.

- The community is well networked with others within its working environment. This includes but is not necessarily limited to political, economic, social, cultural and environmental entities at a local, national and possibly international level. 
- The community is well grounded in where it wants to go and has developed internal checks and balances that keep its rudder in the water. These communities are no longer subject to the "expert/consultant syndrome," a syndrome where a community follows experts blindly.

\section{External Influences Required for Communities to Thrive}

Even with these internal factors an Aboriginal community also needs things from the outside world. The first is a genuine sense of purpose with respect to its lands. This arises out of a willing and respectful land authority and land administration, an effective cooperative planning and management framework between the community and outside land managers, full respect for and use of the community's local knowledge in land planning and management, and innovative industrial players who are willing to step out of their traditional working environment and try new ideas.

All of these internal and external factors must focus to address the full range of aboriginal communities' interests. Many outside groups often carry the mistaken assumption that the aboriginal community's interests are limited to its traditional use of the land. However, an aboriginal community is very similar to other communities in that it has a range of interest generally including but not necessarily limited to:

- Fulfilling its stewardship responsibilities that arise out its long-term cultural connection to and sense of responsibility towards its traditional lands;

- Avoiding activities that unreasonably restrict the community's ability to continue to access and live off the land (exercise its aboriginal rights);

- Identifying, protecting, and managing important cultural heritage resources;

- Protecting areas that are valuable to the community for various reasons, e.g., spiritual, hunting, fishing, recreation;

- Minimizing the host of negative social impacts that are often associated with the impacts of development including the injection of unprecedented monies into remote and often economically depressed areas;

- Benefiting from the primary and secondary economic and employment opportunities associated with development; and

- Preserving the general health of the environment.

\section{Aboriginal Communities and the Forest Sector}

Building a new future that allows us to deal with the forces of globalization in an effective long-term relationship between the forest sector and boreal aboriginal communities contains many challenges. One of the biggest challenges involves the way the forest sector thinks about itself. We need to seriously ask ourselves whether we want to continue to try to keep up with the globalization game or should we simply stop playing the game?

The "stop playing the game" option obviously requires a substantial paradigm shift where the sector must drop the ideal of being a global forest player, increase its focus on meeting domestic needs, increase local involvement and employment in areas where it operates, and generally reduce the sector's impacts on the land. While this is counter-intuitive to the prevailing global culture of bigger is better it is a question worth considering. Canada has a number of significant limitations in terms of being a world force in the forest industry, high labour costs and relatively lower growing rates being small examples. We are structured to compete in and chase the global dream but it is worth asking ourselves if this is really worth it. In order to maintain the forest sector at this level we are creating significant impacts our forest landbase and the people who depend on it. So-can we stay ahead in this game or are we simply in a race to the bottom?

Even if we were to consider the "stop playing the game" option in Canada we have already for the most part tooled up to become a player in the global forest sector. In fact, in most areas of Canada we have over-tooled beyond the physical capacity of the resource. Making the collective decision to change our current direction is difficult because of the complex range of interests involved and implementing this change would prove even more difficult given the deep sacrifices that would be required to give up some or all of those interests.

The decision to change the sector is unlikely in the short term, so we must deal with what we have now. Fortunately, we have somewhat of a base to build from in the fact that much of Canadian thinking, e.g., tolerance, respect for nature, freedom of choice, value for community, is grounded in aboriginal thinking. My theory is that the way that contact between the newcomers and the resident aboriginal population happened in Canada created a great deal of our Canadian philosophical framework. Contact did not happen through war or conquering but rather was more of a steady blending until the creation of Indian Reserves. Many of Canada's most influential newcomers were closely involved (including many marriages) to the resident aboriginal population. Therefore, the inherent beliefs in aboriginal culture are a big part of what makes our country unique in the world.

\section{Guidelines for Working with Aboriginal Communities}

Creating new working relationships between the forest sector and the aboriginal community requires some changes in the way that the forest sector works with the aboriginal community. The following are some guidelines or ideas on how the sector might change.

- Use the Forest Stewardship Council Guidelines in Principle 3 to provide some guidance, but remember that this is not strictly a legalistic standards-based process. This is much more of a human exercise-as is forestry in general.

- Take the time to get to know the aboriginal communities in your operating area-not just the highlights but by spending time engaging at a personal level in the same manner that most forest companies engage with the nonaboriginal communities. A friend who manages a local forest company once asked me for advice on how to develop a better relationship with the local Indian Band immediately adjacent to the municipality where his operations and mill were centered. After a few questions it was clear that his company and he had a great deal of interaction with and a resultant relatively positive relationship with the municipality. I suggested that he might think of the Band as a separate community that occupies the same physical space as the municipality and that he might think about treating them in a manner similar to the municipality in terms of involvement and engagement. I am happy to say that the relationship between the company and the community has improved significantly to the point where they are doing business together because of this simple understanding. To paraphrase a close friend (Chief Sophie 
Pierre), "I was born in your hospital. I went to your schools. I know your language. I got married in your church. I know everything there is to know about you but you know nothing about me. That is the source of our tension."

- Very few communities understand how outside governments work and how the forest sector operates. This is particularly true of boreal aboriginal communities because of their relative isolation and limited internal capacity. Therefore, industry must be actively engaged in teaching the communities about their company, the overall industry and the legal environment that the industry operates within.

- Do not just talk to a few individuals within the community but rather take the time and effort to engage the community as fully as you possibly can. This adds value to your forest management plans and reduces the potential for long-term dissention if done properly.

- Many boreal aboriginal communities have a serious capacity shortage at all levels. Most of these communities are very appreciative of others who willing support internal community capacity development. On a more selfish note, increased community capacity also means that outside entities such as forest companies have a more able community to work with.

- Focus on creating numerous employment and training opportunities and work closely with the community to identify suitable individuals to take advantage of those opportunities. Most communities are more than willing to work by the principle that individuals get a chance because of their heritage but they stay because of merit. Not working closely with the community can result in a situation where your company is always to blame for all of the problems, regardless of their cause.

- Learn how the community lives with the land then shape your operations to fit within the community's lifestyle on the land. My experience is that there is almost always a mutually acceptable way of conducting operations that in many cases can enhance a community's ability to live on the land.

- Treat local knowledge with the respect and value it deserves. It would take most scientists many years of study and many thousands of dollars to learn what most communities have already learned through often thousands of years of living on a piece of land. Develop and follow information-sharing protocols, learn to use local knowledge side-by-side with scientific knowledge, and pay the individuals who provide local knowledge consistent with what you would pay for other experts.

- Create opportunities for those who are interested in capitalizing on economic opportunities. Some companies have even taken this as far as providing seed capital that is deducted from future revenues earned from the company.

- Formalize your relationship with the communities in agreements that provide clarity and certainty on your working relationship. Ensure that the primary focus of these agreements is the creation of a positive working relationship that allows each party to effectively deal with their respective interests.

- Many aboriginal communities have dealt with a long history of a lack of respect for themselves and a lack of recog- nition of their inherent rights. Outside entities can go a long way by starting on a foundation of respect and recognition. Mutual recognition and respect language should be formalized in your agreements.

- Very few communities have the necessary resources to be informed and effective partners in the forest sector. Interested companies must explore a range of options for helping a community to gain access to resources; some options may include conducting various analysis using the community's criteria, train community members on how to read maps and understand forestry jargon, provide independent expert assistance, hire community members in formal liaison positions, provide space for community members to work in, and/or provide cash or other capital required.

- Create a documented dispute-resolution process that is articulated in a formal agreement. Disputes are inevitable so the important thing is to be clear about the process that will be used to resolve those disputes when they arise. Don't just write this-follow it.

One final recommendation that involves a bit more thinking and work is to become a full-fledged forest company. Most communities have a wide range of economic interests related to the forest. A company that is willing to explore and possibly become partners in these other ventures engrains itself into the community fabric over time. Now the company is no longer the culprit that is creating all the harm but rather the partner who is living with and using the land as an extension of the community.

\section{Conclusions}

What is clear is that globalization, the forest sector and boreal aboriginal communities are here to stay. Therefore, the only real question is, "How do we work with each other in this environment?" My belief is that we are all striving for the same thing. I have personally never met a forester that does not care about the land and about the way that people live on the land. I have also never met an aboriginal community that does not believe that the land is there to be used in a wise way. There is a great deal of possible synergy within these overlapping world views and each party has the potential to make a huge contribution towards a partnership that will yield a much higher standard of land care and will be best for the entire world in the long run.

While this discussion has focussed on the Canadian forest sector and boreal aboriginal communities, the thoughts expressed here are equally applicable to the way that we live with people and the land in a global way. The distance that we have to travel in order to look after the world better is a mere 6 "- the distance between our ears. We had everything we needed in order to look after the world properly when we had nothing. It is coming to a collective realization of that fact and acting on it that seems to be the enemy of our species. The old saying that, "the closer idealism comes to reality the more prohibitive the costs" was written for this situation, especially when you consider the range and magnitude of the costs. Even so, the idealistic side of me continues to think that perhaps through acting on the ideas presented here we can begin to do our part and create a model that charts a course for others to follow. Perhaps? 